\title{
Cibernética e Atividades Legislativas
}

IGOR TENÓRIO

Professor da Universidade de Brasília e Membro do Serviço Jurídico da União

SUMÁRIO: 01 - O problema do número excessivo de leis. 02 - O funcionamento do Legislativo e a técnica legislativa. 03 - O áspero caminho da codificação. 04 - Recomendações para a reforma do Poder Legislativo. $05-\mathrm{A}$ posição do Estado de São Paulo. 06 - Padronização de atos administrativos na esfera federal. 07 - A normatividade do processo legislativo como instrumento para a reforma do Legislativo. Projeto Henrique Turner. $08-0$ computador no Legislativo e no levantamento das leis.

\section{1 - O PROBLEMA DO NÚMERO EXCESSIVO DE LEIS}

Tarefa exaustiva seria a de catalogar, mesmo dentro de um critério seletivo, tôdas as opiniões de abalizados autores pátrios, que hajam profligado o excessivo número de leis, cujo conjunto compõe o quadro de nosso Direito positivo.

Partiram de fiscalistas as primeiras condenações.

Tito Rezende chegou a publicar uma relação de quantas leis e decretos sôbre o Impôsto de Renda foram editados em um período de doze meses, fluídos de meados de julho de 1964 a meados de julho de 1965.

Segundo êle, no lapso de tempo considerado, tivemos nada menos de trinta e seis, ou seja, três por mês.

Utilizando totais acumulados, para o periodo de julho de 1964 a janeiro de 1966, anotou a existência de cinqüenta e oito novos diplomas legais que, expressa ou implicitamente, alcançavam aquêle tributo. E chamou ao resultado de "sucessão alucinante de leis e decretos". Sugeriu, então, que se deveria pensar, antes de se fazer umas e outros, a fim de evitar fôssem baixadas novas normas, antes mesmo da vigência das recém-publicadas, como correção a "disposições infelizes, iníquas, inexeqüiveis ou ineptas". 
Outro cultor do Direito Tributário, o Dr. Otto Gil destacou que, no Brasil, de há muito, lutam os contribuintes de impostos, taxas e contribuições, notadamente dos da competência tributária federal, por uma reformulação das leis vigentes. Essa reformulação deveria assegurar, em relação ao contribuinte, o cumprimento de seus deveres perante o Fisco. E, em relação à Fazenda Pública, asseguraria o exercício da atividade fiscal "dentro de leis eqüitativas, redigidas com clareza e aplicadas com justiça". E aduziu não ter nenhuma esperança de que tal estado de coisas possa melhorar, "pois cada reforma que se propõe ao Congresso (e que êste aceita para atender aos propósitos do Executivo) é sempre para coartar, cada vez mais, o direito do contribuinte face ao insaciável Moloch, que é o Erário Público, no Brasil".

$\mathrm{Na}$ mesma linha de pensamento, ao lançar sua série de Manuais Fiscais, a ASPLAN (Assessoria em Planejamento S.A.) destacou a crescente complexidade de nossa legislação tributária. De tal fato advém a dificuldade quanto ao exato cumprimento dos preceitos legais, face à dispersão de leis, decretos, regulamentos, portarias e ordens de serviço que, sem nenhuma sistemática, cuidam da matéria.

Essa falta de unidade é marcante característica da legislação fiscal e administrativa.

Por isso, o editor dos Manuais Fiscais ASPLAN situou a difícil posição do contribuinte: está obrigado a múltiplas consultas a textos legais; essas pesquisas são demoradas, onerosas e, às vêzes, improfícuas. E mais, ainda assim, sujeita-se a penalidades por infrações involuntárias, "decorrentes de interpretação errônea e motivada, até, pelo conhecimento incompleto de tôdas as normas contidas naqueles atos esparsos".

Além de tudo, o próprio modo de elaboração e tramitação legislativa, em regime de urgência, para assunto tão complexo, "conduz à aprovação de leis com redação imprecisa e defeituosa e, quase sempre, sem a necessária organicidade".

Noutra publicação da ASPLAN, na nota introdutória, repisou-se o modêlo já costumeiro em obras de tal categoria, com reparos relativos às sucessivas e excessivas alterações introduzidas na legislação tributária federal. A crescente edição de textos legislativos, que se fazem acompanhar de outros tantos, regulamentares, concorre para uma verdadeira pletora de disposições desarmônicas, dificultando, sobremaneira, o "entendimento e, até mesmo, o simples acompanhamento das normas em vigor". 
René Izoldi Ávila comenta o espetáculo oferecido pelos vendedores que, nas ruas, apregoam a última Lei da Previdência, a nova Constituição, as últimas alterações das Leis do Trabalho, o nôvo Código de Trânsito etc., etc.

Sem dúvida, o estrangeiro aqui chegado pensará estar pondo os pés no país de maior cultura jurídica do planêta.

\section{"No Brasil de hoje - acrescenta - vendem-se leis na rua, como pipoca e amendoim. \\ $E$ êsse fenômeno não é senão a conseqüência da inflação de textos legais, que tomou conta da Nação nos últimos anos."}

Com a sua reconhecida autoridade profissional, o Dr. Seabra Fagundes, em 25 de agôsto de 1970, ao discursar quando da inauguração da nova sede do Instituto dos Advogados de São Paulo, como presidente do Instituto dos Advogados Brasileiros, combateu, também, o excesso de leis. Enumerou que de 26 de abril de 1964, com a Lei n? 4.326, cuja sanção inicia o ciclo Legislativo do primeiro Govêrno Revolucionário, até 9 de fevereiro de 1967, com a última por êle promulgada (Lei número 5.252 ), alcança o total de 926 leis.

A enumeração continua, para listar os 37 atos complementares, e mais 318 decretos-leis. Do conjunto dêsses últimos, 207 foram baixados nos 50 dias que vão de 24 de janeiro a 14 de março de 1967, o que dá a média de 4 por dia.

Continuando a sua análise, frisou que o Presidente Costa e Silva subscreveu, em 2 anos, 6 meses e 5 dias de govêrno, 435 decretos-leis. E a Junta Militar, em menos de 60 dias, promulgou 263 decretos-leis. Com êsses dados, procurou situar a complexidade do panorama legislativo, área específica da atuação dos advogados.

Exemplificou que no campo tributário, tantos são os atos normativos que, conhecê-los, se tornou uma especialização profissional e privilégio de alguns.

Reportando-se a um depoimento de Afonso Almiro, emérito tributarista, citou que a consolidação do Impôsto de Renda tentada pelo Decreto n० 58.400 , como Regulamento do mesmo, abrange 58 leis, 12 decretos-leis e 14 decretos. Entre a data de Sua publicação, maio de 1966, até 10 de outubro de 1968, o Impôsto de Renda foi alterado 174 vêzes, "sendo 33 por leis, 66 por decretos-leis e 75 por decretos. Isto sem mencionar a abundante e muitas vêzes conflitante legislação delegada (Resoluções do Banco Central do Brasil, da CONEP etc.)". 
Outra catalogação do inflacionamento da legislação pode ser colhida em trecho de discurso proferido em 16 de setembro de 1970, pelo Deputado Henrique Turner, no Plenário da Câmara Federal.

Aludiu ao fato de que até 1934 foram expedidos 24.668 decretos com fôrça de lei; entre 1935 e 1937, vieram a lume 586 leis. E continuou sua lista: entre 1938 a 1946 foram editados 9.913 decretos-leis. De 4 de outubro de 1946 a 15 de julho de 1970 , promulgaram-se mais 5.590 leis, afora 1.113 decretosleis. Os totais são também impressionantes:

$$
\begin{aligned}
& \text { Leis e atos com fôrça de lei ......... } \quad 42.170 \\
& \text { Decretos ....................... } \quad 66.884 \\
& \text { Total ......................... }
\end{aligned}
$$

Já o Dr. Carlos A. Dunshee de Abranches, em artigo, salientou que, em recente data, o Conselho Federal da Ordem dos Advogados do Brasil aprovou indicação "na qual se declara que diàriamente surgem dúvidas quanto à legislação, mesmo entre aquêles que por dever de ofício são obrigados a conhecer os textos operantes, tais como ministros de Estado, consultores, chefes de repartições, advogados e juízes".

Exemplificando com o capítulo de locação, o Dr. Carlos A. Dunshee de Abranches afirma que, por fôrça das imperfeições, mudanças de critério e falta de unidade que apresentam as sucessivas leis de inquilinato, dificilmente locadores e locatários conhecem, com exatidão, seus direitos e obrigações. Em conseqüência, há os litígios desnecessários e maliciosos que resultam no acúmulo de ações nas varas e nos tribunais. O exemplo aplica-se, por igual, à legislação financeira, tributária, trabalhista, previdenciária e agrária, colchas de retalhos e diabólicos quebra-cabeças jurídicos.

Como facêta de nosso subdesenvolvimento cultural, a pletora de leis revela a fraqueza do sistema de Direito positivo e, conseqüentemente, o estrangulamento que se deve enfrentar ao tomar-se a tarefa de revitalização da chamada área das profissões legais.

Damos, ao final, a palavra ao Ministro do Supremo Tribunal Federal:

"Sob a vigência da atual Constituição, de setembro de 1946 a dezembro de 1958, isto é, num período de pouco mais de doze anos, o Congresso brasileiro votou 3.520 leis, média de cêrca de $\mathbf{3 0 0}$ por ano, e o Presidente da República expediu 22.288 decretos, média anual de 
quase dois mil. Vale dizer que o Presidente da República, em cada dia útil, sanciona uma lei e expede meia dúzia de decretos. Que êle não possa dar atenção acurada a essa massa legislativa é coisa que, evidentemente, dispensa demonstração."

\section{2 - O FUNCIONAMENTO DO LEGISLATIVO E A TÉCNICA LEGISLATIVA}

Afora os reparos à legislação copiosa e complexa, deve o advogado enfrentar a irmã-siamesa, que é a descuidada técnica de redação das leis. $O$ quadro se completa com as deficiências do Legislativo, que ainda está imune à renovação e atualização de nossos tempos.

O Dr. Seabra Fagundes aludiu ao problema da feitura das leis, observando que a sub-rogação tentada, e intensamente, do bacharel pelo economista, foi uma experiência frustrada. Di-lo aquêles aos quais as leis se endereçam. Refere-se ao fato de que qualquer locatário ou locador conseguiria alcançar, nas leis do inquilinato, algo de seu sentido. Hoje, com a Lei no 4.494, de 23 de novembro de 1964, "de origem nada bacharelesca", o sentido é oculto e a percepção dificultada, afora aos iniciados, quanto à inteligência do que se deve compreender por fator $\mathrm{K}$, valôres $C$ e D, etc. E adianta o Dr. Seabra Fagundes, tomando - Estatuto da Terra, demonstrando como é confuso o jôgo de remissões para extrair-se um significado lógico aos conceitos de "imóvel rural", "propriedade familiar", "módulo rural", "minifúndio", "latifúndio", "emprêsa rural", "parceleiro", "cooperativa integral de reforma agrária", "colonização" etc. É um exemplo de lei redigida por pessoas alheias à técnica de legislar.

Outro exemplo é o do Decreto-lei no 43 , de 18 de novembro de 1966, "e perceber-se-á que não foram bacharéis os que atribuíram ao Instituto Nacional de Cinema conceder certificado de cidadania brasileira aos filmes produzidos no País".

Lembrando que suas palavras não são de desaprêço ao mérito dos profissionais de economia, mas tão-sòmente uma reivindicação da teoria da especialização do trabalho, concluiu por afirmar que fazer leis é tarefa de bacharéis, quando advogados, juristas ou políticos.

O Ministro Oswaldo Trigueiro, em conferência sôbre as tarefas legislativas do Congresso, pronunciada na Universidade de Brasília, já havia feito o reparo de que "a maioria das leis votadas anualmente inclui-se na categoria das leis meramente 
formais". O Congresso vota poucas leis, e essas mesmas, pelos defeitos do processo legislativo, "não são evidentemente da melhor qualidade".

A ocasião, o então Deputado Ernâni Sátiro tomou uma cautelosa posição em relação à validade das delegações legislativas, pois poderia citar exemplos do perigo dessa prática, comentando:

"Somos testemunhas, muitas vêzes, de certos projetos remetidos pelo Executivo, verdadeiros monstrengos, de onde extraímos as coisas mais estúpidas.

E também se trata de atitude impessoal, não só neste, mas em outro govêrno qualquer.

Sei qual tem sido o trabalho da liderança do govêrno, muitas vêzes até particularmente devolvendo projetos a alguns ministérios, onde, outras vêzes, êsses projetos são elaborados por pessoas sem a menor experiência, sem a menor competência e, em alguns casos, que não são nem legisladores, porque até agrônomos, porque até eletricistas têm feito projetos de lei neste Brasil.

Imagine-se o que acontecerá se fôr concedida essa delegação em têrmos amplos; se, ao invés de serem essas proposições remetidas ao Congresso Nacional, forem, desde logo, através de delegação, transformadas em lei."

Em recente data, Vicente Ferrer Correia Lima esclarecia que, no Brasil, é corrente o entendimento de que qualquer pessoa de mediana ou de cultura superior porta aptidão para redigir diplomas legais, "quando nem todo profissional de direito o faz com a perícia recomendada pelos especialistas".

$\mathrm{E}$, indo além, profligou o empirismo predominante no Brasil, quanto à preparação de profissionais na difícil arte de redigir leis. É claro que os princípios desta técnica, seus preceitos, que comandam o preparo de um projeto de lei, enfim, o domínio da complexa técnica legislativa, são imprescindiveis para a produção da peça jurídica. O redator da mensagem há de ater-se à valiosa recomendação da meridiana clareza e da máxima objetiva, atendendo à opinião de Reed Dickerson, que nos fala: "A redação de projetos de lei deve ter a precisão da engenharia; a minudência e a coerência da arquitetura, pois é a arquitetura jurídica."

Vicente Ferrer Correia Lima inscreve-se no rol dos que julgam necessária uma atitude ante as mudanças continuadas da 
legislação, para situar-se dentro do seguinte raciocínio: "Nada mais sensato que se inovasse também no campo vital da ação legislativa do Govêrno, o que asseguraria seu sucesso com número reduzido de excelentes leis e a vantagem de dificilmente serem elas ultrapassadas pelos modernos e futuros hábitos da civilização."

Porém, quem mais veementemente condenou o despreparo geral para as tarefas legislativas foi o Prof. Lydio Machado Bandeira de Mello. Perguntou, em conferência feita no II Congresso Nacional de Direito Penal, por que o Congresso Nacional não elaborava um nôvo Código Penal.

E deu sua resposta, como "verdade nua e crua: Porque noventa e cinco por cento dos Senhores Deputados e Senadores não sabem organizar e redigir um código".

Culpou, pela situação, as próprias faculdades de Direito, que não ensinam a técnica de elaboração e da redação das leis. Preparam juízes, promotores e advogados, porém se esquecem, por completo, de formar legisladores.

Esclareceu que os métodos de ensino, para um e outro desempenho, não podem ser uniformes. Ter-se-ia de distinguir o preparo do legislador, em tudo diverso daqueloutro necessário ao aplicador da lei. Os juízes, os promotores e os advogados trabalham com o Direito Penal vigente. O legislador, além do conhecimento da técnica legislativa, do próprio Direito Penal, deve saber muito mais do que os primeiros. Em suas palavras: "Devem saber tirar um Código do Nada relativo, ter a noção exata dos valôres da vida a serem tutelados pelas leis penais, estar em condições de relacionar, classificar e definir os crimes, os delitos e as contravenções e de quantificar as penas depois de medir a gravidade das infrações penais."

E, como as escolas se esquecem de formar legisladores, não se chega, por igual, a uma teoria geral da parte especial do Código.

Nessa seqüência, temos observado o excesso de leis, a pobreza de sua construção doutrinária e técnica, a sua falta de organicidade e de sistemática, os defeitos de funcionamento do Legislativo e, finalmente, a raiz do mal, que brota a partir do tipo de ensino jurídico que vem sendo ministrado nas escolas de Direito.

\section{3 - O ÁSPERO CAMINHO DA CODIFICAÇÃO}

Não obstante as evidentes vantagens da codificação, em cada ramo do Direito, há necessidade de um grande esfôrço 
intelectual para cobrir-se, em conjunto, tôda uma área de disciplina jurídica autônoma. Há necessidade de uma filtragem, pelo tempo, da experiência adquirida. Há problemas específicos de cada disciplina, afora peculiaridades culturais do Brasil, decorrentes das chamadas desigualdades regionais. A êsse propósito, o prof. Roberto Lyra prestou valjoso depoimento sôbre o anteprojeto de Código das Execuções, de sua autoria:

"O legislador federal viciou-se na visão próxima. Quando se distanciava da antiga capital litorânea, procurava as frondes alienígenas. Cumpria-me inaugurar uma cintura jurídica, atendendo aos melindres de um diploma a ser locado nas fronteiras institucionais entre a União e os Estados e entre o Poder Executivo e o Poder Judiciário. Há Estados vanguardeiros que devem ser desembaraçados de miudezas e fantasias. Os textos do anteprojeto são adaptáveis às peculiaridades e condições dos Estados. Isto não exclui os padrões nacionais, os pontos de honra de nossa civilização. Em nosso Direito Penal, a própria legislação substantiva deve ser federativa e não sòmente federal. Escrevi há quatro anos: "Colaborei em obra de unificação - a do Código de Processo Penal. Os fatos obrigaram o meu espírito público a evoluir. A escola brasileira é pela pluralidade e pela periodicidade dos Códigos (NINA RODRIGUES, AFRÂNIO PEIXOTO etc.) para atender às diversidades regionais e à mobilidade social (ROBERTO LYRA, Visão Doutoral do Direito Penal Comparado, Rio, 1961, pág. 13)."

Êsse desvêlo cumpre ser preservado em tôdas as experiências de codificação.

É conhecida a lição da revolta do fato no mundo jurídico.

Fazendo sua observação em tôrno do tema, o prof. Alfredo Augusto Becker teve ocasião de destacar: "Em todos os ramos do Direito e principalmente no Direito Tributário, o fato está em rebelião contra o jurídico e o linguajar jurídico atual multicoloriu-se de expressões que denunciam a homenagem que os juristas, hoje, rendem ao fato: fato gerador, contribuinte de fato, domicilio de fato, tutela de fato, separação de fato, sociedade de fato, filiação de fato etc."

E esclarecendo o problema da simplificação do Direito Positivo, destaca que a rebelião é impulsionada por diversos 
fatôres. Reportando-se a R. Salvatier, cita: "Primeiro, o desejo por uma simplificação do Direito Positivo; segundo, o prodigioso desenvolvimento das ciências consagradas ao estudo dos fatos sociais; terceiro, o realismo degenerado em mística."

\section{4 - RECOMENDAÇÕES PARA A REFORMA DO PODER LEGISLATIVO}

Pesquisando-se o material que a Câmara dos Deputados editou sob forma de livro "A Reforma do Poder Legislativo no Brasil", 1966, verifica-se que as sugestões em tôrno do problema não se limitam a uma faixa simples de variações.

O Prof. Oswaldo Trigueiro, atual Ministro do Supremo Tribunal Federal, defendeu, no contexto, a tese da delegação de podêres e a incorporação ao texto permanente da Constituição das normas transitórias do Ato Institucional, pertinentes ao processo legislativo. (Solução da atual Constituição.)

Porém, o receituário abrange tôda uma gama; transferência de podêres para determinados órgãos técnicos; prazos fatais para a elaboração legislativa; restrições à capacidade de iniciativa de projetos de lei; exclusividade da iniciativa ao Chefe do Poder Executivo, em certas matérias; alteração no fluxo da discussão dos projetos, para economia de tempo; casos de elaboração legislativa em caráter urgente e conjunta pelas duas Câmaras; delegação de competência; fiscalização, pelo Congresso, dos atos do Poder Executivo e da administração descentralizada etc.

Ao rol acima lembramos, ainda, as sugestões de José Afonso da Silva: delegação de podêres e legislação delegada; sistema de atribuição de podêres residuais; autorização para expedição de decretos-leis; sistema de atribuição da competência às comissões; entrega de funções legislativas às comissões, preservadas as políticas ao plenário etc. E, finalmente, seguindo idéia inicialmente exposta por Rosah Russomano de Mendonça Lima, propõe que se criem Conselhos de Legislação, formados de juristas e outros técnicos de renome nacional, para cuidar da técnica de redação das leis.

Êsses caminhos, clássicos e conhecidos, devem ser complementados pela utilização do computador na guarda, classificação e acompanhamento de projetos; no levantamento da indispensável documentação necessária à consulta no processo de elaboração legislativa; na reformulação e consolidação da legislação atual; no emprêgo de simulação, como meio eficiente 
de se testar disposições novas a serem introduzidas no sistema jurídico etc.

Vamos, daqui por diante, examinar as novas aberturas trazidas pela tecnologia e pela experiência, capazes de remediar e de reduzir o impacto de tôdas essas deficiências.

\section{5 - A POSIÇÃO DO ESTADO DE SÃO PAULO}

Tomando a iniciativa de uma ampla reformulação legislativa, o Govêrno de São Paulo, em fins de 1969, determinou a consolidação de 60 mil leis, decretos e outros atos normativos, para reduzir êsse acervo a apenas pouco mais de 100 atos.

Conforme determinação legal baixada pelo Govêrno daquele Estado, as leis, decretos e atos administrativos de conteúdo normativo e de caráter geral e permanente "serão revistos, atualizados, ordenados e consolidados". Foram adotadas, ademais, as seguintes providências:

a) Prazo de 60 dias, para que a administração centralizada e descentralizada do Estado procedesse ao "exame, tiragem e seleção das leis estaduais, relacionadas com a respectiva competência, agrupando, atualizando e consolidando em projeto de decreto-lei as que, em vigor, tratam do mesmo assunto ou de assuntos vinculados, por relação de pertinência, conexão ou afinidade, e indicando expressamente ou implicitamente as revogadas ou derrogadas".

b) Referência de origem, após cada disposição consolidada (indicação da norma legal da qual se filia).

c) Estabelecimento de um mecanismo de triagem para novas disposições legais. Cada proposta deve ser encaminhada com justificação; deve observar, quanto à técnica legislativa, aos preceitos do Decreto-lei Complementar nọ 1, de São Paulo; a proposta se sujeita a parecer da Assessoria de Técnica Legislativa; será, após, remetida à Comissão Especial instituída pelo ato de 3-3-69, e só então, logrando parecer favorável, é que será submetida ao Governador do Estado.

d) Nova numeração das leis estaduais, a partir do final do recesso da Assembléia Legislativa; bem como nova seriação para decretos e atos administrativos, após a conclusão do trabalho de consolidação dos atos administrativos de conteúdo normativo e de caráter geral e permanente.

e) Nomenclatura de atos administrativos, com designação específica, por autoridade, de cada ato: decreto, deliberação, portaria. 
Estabelecendo normas para o processo legislativo, por igual, foi baixado o Decreto-lei Complementar no 1 , de 11 de agôsto de 1969.

São nove artigos que enfeixam o essencial.

Inicia o artigo primeiro com determinação quanto à numeração das leis e decretos de conteúdo normativo e caráter geral, que terão número seguido, sem renovação anual. Os atos de conteúdo específico e individualizado não terão número, caracterizando-se pela data. Exclui o artigo subseqüente do texto de lei qualquer matéria estranha ao assunto que constitui seu objeto, ou vinculado por conexão, afinidade ou pertinência, conforme o enunciado da respectiva ementa. Por igual, o mesmo assunto não poderá ser disciplinado por mais de uma lei ou decreto. Ressalvaram-se a hipótese de alteração ou complementação da lei ou decreto, cabendo remissão expressa. 0 artigo terceiro é consagrado ao mecanismo de alteração da lei ou decreto, que se reduz à reprodução do texto, com incorporação ao mesmo da alteração, e sua nova publicação, consolidada.

O artigo quarto exige estrita observância, quanto à técnica legislativa, dos postulados de clareza, precisão, ordem lógica etc.; o corpo da lei se subdividirá em título, ementa, artigos numerados e desdobramento de artigos em parágrafos, itens, incisos e alíneas. O agrupamento de artigos constitui seção; estas perfazem o capítulo; o conjunto de capítulos representa o título; e dêstes, livro. Cada livro pode ser desdobrado em parte geral e parte especial. Permitem-se disposições preliminares, gerais e transitórias, em lugar próprio. Cada lei deve sempre, e expressamente, declarar qual a legislação anterior que é revogada ou derrogada.

$O$ artigo quinto trata de normas semelhantes, em relação aos atos administrativos, matéria ainda dos dois artigos subseqüentes.

O cumprimento das normas estabelecidas no decreto-lei complementar passou à competência da Chefia da Casa Civil do Govêrno de São Paulo.

Essas padronização e consolidação legislativas estão justificadas em exposição de motivos subscrita pelo dr. José Henrique Turner, então Chefe da Casa Civil, que se socorreu dos seguintes principais argumentos para respaldo de sua proposição:

19) A grave inflação na área da legislação estadual, com danosos reflexos na atividade do cidadão, pela dificuldade e tumulto resultante da consulta aos textos. 
20) A legislação é, em si mesma, densa e complexa.

3 ?) Há tôda a conveniência em reduzir-se o atual número de leis, $\mathbf{9 0} \%$ de conteúdo específico, ou seja, leis sòmente no aspecto formal.

4 ị) Conveniência de valorizar-se a designação de leis para "os atos de conteúdo normativo e caráter geral e permanente" como "desestímulo ao excesso legisferante nos setores que envolvem reduzido significado social."

\section{6 - PADRONIZAÇÃO DE ATOS ADMINISTRATIVOS}

NA ESFERA FEDERAL

Exemplo de significativa atualidade quanto às possibilidades de padronização de atos repetitivos é-nos trazida pela Circular no 7 , de 9 de dezembro de 1969, expedida pelo dr. João Leitão de Abreu, Ministro Extraordinário do Gabinete Civil.

Dita Circular traçou normas para o procedimento uniforme dos atos submetidos à assinatura do Presidente da República.

A padronização é obrigatória em relação aos "projetos de decretos executivos ou decretos pessoais de nomeação, exoneração, designação, dispensa, retificação e alteração do texto".

Como se sabe, em linhas semelhantes é que se programam os computadores a serviço de legislativos estaduais, nos Estados Unidos, facilitando a uniformidade do procedimento legislativo.

\section{7 - A NORMATIVIDADE DO PROCESSO COMO INSTRUMENTO PARA A REFORMA DO LEGISLATIVO \\ - Projeto Henrique Turner}

O processo legislativo, a partir de 1967, integra o texto constitucional e, pela Emenda Constitucional n? 1/69, compreende os arts. 46 a 59.

Ademais, essas normas são aplicáveis aos Estados, visto o disposto no art. 13, item III, da Carta Magna.

Assim, se um projeto de lei referir-se ao tema, como de cumprimento da Constituição (art. 8.?, item XVII, alínea "a"), introduzir-se-á no ordenamento jurídico norma de caráter federativo ou nacional, em vez de simples lei federal.

Embora o acima seja apenas uma dúvida de caráter teórico, terá de ser alvo de melhor exame, quando da tramitação 
do Projeto Henrique Turner. O parlamentar paulista, com sua experiência de ex-Chefe da Casa Civil do Govêrno de São Paulo, apresentou, em uma só proposição, um projeto de lei complementar que engloba os dois atos baixados, em São Paulo, sôbre o processo legislativo. Designou-o, expressamente, como lei complementar e, como tal, votada pela maioria absoluta das duas Casas do Congresso Nacional. (Constituição, art. 50.)

Além de sua justificativa, em defesa da tese, o autor usou da tribuna, em 16 de setembro de 1970, para explicar a assertiva de que a reforma do processo legislativo é o passo inicial da reforma do Legislativo.

Como nos parece merecer a melhor meditação o projeto em aprêço, devemos acrescentar que a matéria guarda interêsse e atualidade. De fato, como o Congresso deseja reconquistar suas prerrogativas, deve, paralelamente, reforçar seu esquema de funcionamento, numa verdadeira Reforma Administrativa do Legislativo, e que bem começará pela proposta do representante paulista.

Contudo, no projeto, esqueceu-se o Deputado Henrique Turner de contemplar, como incluídas nas normas de metodização, as leis delegadas, os decretos legislativos e as resoluções.

Porém, pelas facilidades de sistematização trazidas em seu bôjo, pela rapidez com que se dirá quanto ao nascimento e alterações e revogações de um texto legal; e, finalmente, pelos defeitos a que se dirige, por evitá-los, no tocante à técnica legislativa, o Projeto Henrique Turner poderá ser a oportunidade inicial para grandes reformas no Congresso, reformas essenciais quanto ao seu próprio funcionamento e à qualidade do produto final, resultante de sua atividade - a lei brasileira.

\section{8 - O COMPUTADOR NO LEGISLATIVO E NO LEVANTAMENTO DAS LEIS}

Atualmente, por uma conjugação de esforços entre a Casa Civil da Presidência da República e as Mesas da Câmara dos Deputados e do Senado Federal, está em vias de execução, pelo Serviço Federal de Processamento de Dados (SERPRO), a primeira fase de introdução da computação no Legislativo. Será destinada a indicar iniciativa de projetos afins, conexos etc., numa espécie de grande serviço de referência legislativa.

Embora ainda não se disponha de informações conclusivas, já se pode anunciar que, saindo da fase das cogitações, o 
SERPRO se entrosou com os mecanismos de cúpula do Executivo e do Legislativo, levando avante uma audaciosa concepção técnico-jurídica, e que será, quando concluída, um modêlo para os países de direito de origem romana.

$\mathrm{Na}$ atual fase, o projeto está atacado no tocante à escolha e instalação de equipamento, elaboração de programação, treinamento de pessoal e esquemas iniciais de funcionamento, prevendo-se sua definitiva implantação para o decorrer de 1971.

Porém, outro exemplo a ser citado é o da Assembléia Legislativa de Goiás que, através de assessoria do Instituto de Pesquisas e Estudos Parlamentares, está pondo em prática amplo projeto de modernização e atualização.

A partir de março de 1971, além de instalação mais amplas e completas, contará o Legislativo goiano com computação eletrônica, como equipamento indispensável ao propósito de colocá-lo nos moldes mais modernos. O principal alvo será o uso de ordenador ou computador para as tarefas de pesquisa, facilitando os trabalhos dos deputados na coleta de dados e de elementos essenciais ao bom desempenho de suas funções específicas. Além disso, a Assembléia Legislativa está querendo armazenar dados de natureza econômica e estatística para permitir estudos de interêsse político, administrativo e de planejamento, no mais amplo sentido do têrmo.

Outro projeto já noticiado pela imprensa, com a designação de DATAJUR, é uma iniciativa conjunta do Serviço Federal de Processamento de Dados (SERPRO) e da Pontíficia Universidade Católica do Rio de Janeiro, com a efetiva participação dos professôres Alexandre Luís Mandina, João Luís Coelho da Rocha e Davi Reis, todos da área de Direito.

Estão sendo ordenados textos legais, dados jurisprudenciais e decisões dos tribunais, num ambicioso plano, ora em fase de programação. Informa-se que o Projeto DATAJUR foi iniciado há seis meses. Os dados técnico-jurídicos estão sendo fornecidos, à máquina, enquanto os especialistas elaboram os programas do computador. Nos próximos dois anos ter-se-á maior facilidade na consulta aos atos normativos na esfera federal e seguir-se-ão o levantamento da jurisprudência e da doutrina, através da técnica de palavras-chave. Quando concluída a fase da execução, qualquer consulente poderá pedir a legislação aplicável a um caso, antecedentes jurisprudenciais e uma súmula da doutrina correlata.

Tudo o que escrevemos leva à conclusão que são grandes e complexos os problemas de renovação do Direito e de apli- 
cação da Cibernética ao campo legislativo. Porém, essas dificuldades que pareciam, no passado, quase insuperáveis, estão sendo, aos poucos, objeto de meditação e de formulação em soluções trazidas pela tecnologia. Padronização, aprimoramento da técnica legislativa, novos critérios de funcionamento, outros paradigmas para o funcionamento do Legislativo, o uso de simulação no processo de exame das leis, o armazenamento de dados técnicos de tôda a ordem etc. são, hoje, possíveis graças ao prestimoso auxiliar que é o computador. As achegas de especialistas em áreas tão diversas, como a Biblioteconomia, o Direito, a Engenharia eletrônica, a Administração científica etc. permitem imaginar o rejuvenescimento de um dos podêres da República, e cujo fortalecimento garantirá a perenidade da democracia e do desenvolvimento econômico e social, nos moldes em que todos almejamos, num país que é grande pela extensão territorial e pelo ideal de seus filhos.

BIBLIOGRAFIA

1 - Rezende, Tito - "Incentivos Fiscais à Estabilização de Preços", 1966.

2 - Gil, Otto - "A Reformulação de Nosso Sistema Tributário", separata, "Revista das Sociedades Anônimas".

3 - Asplan S. A. (Assessoria em Planejamento) - "Manuais Fiscais ASPLAN", 1 (Lei no 4.357, Correção Monetária, Retenções na Fonte).

4 - Ávila, René lodi - "Incentivos Fiscais do Mercado de Capitais".

5 - Abranches, Carlos A. Dunshee - "Legislação, Justiça e Computadores", artigo na "Revista da OAB-DF", no 3, 1971.

6 - Câmara dos Deputados - "A Reforma do Poder Legislativo no Brasil", que contém a palestra do Ministro Oswaldo Trigueiro, então Procurador-Geral da República, pronunciada em 18-8-65, na Universidade de Brasilia.

7 - Fagundes, M. Seabra - "A Legalidade Democrática", "Revista da OAB-DF", no 1, 1970.

8 - Lima, Vicente Ferrer Correia - "A Redação das Leis e o Contencioso Administrativo", "Revista do Serviço Público", Vol. 105, no 3, 1970.

9 - Ministério da Justiça - "Anais do II Congresso Nacional de Direito Penal e Ciências Afins".

10 - Tenório, Igor - "Direito e Cibernética".

11 - Tenório, Igor - "Curso de Direito Financeiro Braslleiro".

12 - Tenório, Igor - "Novas Funções do Legislativo" (In "Jurídica", n’ 104, 1969).

13 - Becker, Alfredo Augusto - "Teoria Geral do Direito Tributário".

14 - Silva, José Afonso - "Princípios do Processo de Formação das Leis no Direito Constitucional".

15 - O Globo, noticiário de 14-8-69, pág. 11.

16 - Correio Braziliense, noticiário de 22-11-70, 2: caderno.

17 - Jornal do Brasil, noticiário de 5-3-71, pág. 10. 


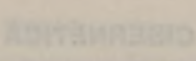

